\title{
Public deliberation as a teaching andragogy: Implications for adult student learning from a doctoral higher education policy course
}

\author{
Matthew Johnson ${ }^{1}$, Margaret Partlo², Tammy Hullender ${ }^{2}$, Emmanuel Akanwa $^{2}$, Heather \\ Burke $^{2}$, Jerry Todd ${ }^{2}$, and Christine Alwood ${ }^{2}$
}

\begin{abstract}
Public deliberation provides an inclusive and robust mechanism for making shared decisions in community and political settings; however, its application to teaching and learning remains underutilized (McMillan \& Harriger, 2007). This manuscript reports on a case study of the use of public deliberation as a teaching andragogy in a doctoral-level course in higher education policy, which showed that public deliberation creates greater ownership of the course, fosters critical thinking and student agency, and implicates taking action.
\end{abstract}

Keywords: Public deliberation, adult learners, andragogy, graduate students, higher education policy

\section{Introduction}

Public deliberation allows participants to make shared decisions about complicated societal issues in community and political settings. Models for public deliberation vary, but developing citizens' voices and creating a shared sense of responsibility and action are central to the process. The Deliberative Democracy Handbook (Melville, Willingham, \& Dedrick, 2006) posits five characteristics of public deliberation: (1) including all voices, not just experts, (2) equal opportunity for participation, (3) creating or using choice work to make decisions, (4) including diverse stakeholders, and (5) seeking common ground. These characteristics distinguish public deliberation from other forms of discussion, which may have similar or contrasting attributes or aims. Public deliberation specifically differs from the other forms of discussion by first promoting understanding of complicated topics where unclear agreement currently exists and then collectively deciding what action should be taken. By finding and building upon the strengths, rather than the weaknesses within the opinions expressed by others, participants suspend judgment in favor of finding common ground, consider the tradeoffs of proposed actions, and decide how to act.

While there are many forms of public deliberation, the specific form of public deliberation used in the current study most closely mirrors the National Issues Forum (NIF) model (nifi.org). The NIF is a non-partisan network of individuals and organizations that advocate for increased citizen participation in public deliberation. The NIF model requires the creation of an issue book to engage stakeholders in a deliberation around a topic or issue of public concern. Issue books contain two main parts - naming and framing. The naming portion of the issue book requires the authors to name an issue of public concern in a way that requires citizens to act. The naming section provides an overview of the problem, contains several strategic facts, and articulates the parameters of the problem. Issues for public deliberation lack

\footnotetext{
${ }^{1}$ Assistant Professor of Educational Leadership, Central Michigan University, johns9m@cmich.edu

${ }^{2}$ Doctoral Student, Central Michigan University
} 
clear answers or technical solutions; rather, they require thinking about issues in complex ways and broad-based action.

Once an issue is named, three or four options to address the problem are created, in the framing section. Each option is distinct from the others and represents a set of related possible actions to address the issue. Additionally, each approach contains a set of related tradeoffs that might accompany action items. During the subsequent issue forum to deliberate the topic using the issue book, trained moderators, who act as neutral parties, guide participants through the issue guide by asking questions and encouraging participants to think critically about the issue and possible approaches suggested. Moderators help pace the deliberations so that each approach receives equal consideration. Moderators also facilitate group follow-up and potential future meetings.

The lead author of this paper, a higher education instructor in a graduate program, was familiar with public deliberation in community settings, but less familiar with its applications to the classroom. In preparing to teach a doctoral-level higher education policy course, two dynamics were important in considering the course's design. First, he wanted students to have a sense of ownership and responsibility over the myriad, complex issues inherent to higher education policy. He sought to avoid focusing only on the role of state and federal policymakers and intellectualized learning about higher education policy. Second, he wanted to engage the affective domains embedded in higher education policy alongside the cognitive domains that tend to dominate policy discourse. Higher education is a deeply held value in American society, and people often have strong emotions toward issues of access, cost, choice, aid, and accountability. For these reasons, he decided to use public deliberation as an andragogy (i.e., teaching strategies for adult learners) in the course. A more thorough description of the course and study are presented in the methods section.

\section{Literature Review}

\section{Public Deliberation Overview}

Melville et al. (2006) described public deliberation as a process encouraging reflection and critical discourse through civic engagement. Participants in public deliberation work collaboratively toward solutions as the deliberative process informs and inspires voice and consensus building (Muse, 2009). Promoted by the National Issues Forum since 1981 as a form of democratic action, public deliberation is an effective method to resolve community issues that require participant involvement in order to influence change (nifi.org).

Public deliberation provides a framework to resolve issues in which participant involvement generates interest in sustainable change. The deliberative process emphasizes participant action rather than reaction and, when used in public forums, develops openness to the views of others. Deliberation also promotes informed consensus, when applied to local environmental issues (Daniels \& Walker, 1996; Harris, Nielsen, Becker, Blahna, \& McLaughlin, 2012), participant involvement in community healthcare forums (Downey, Anyaegbunam, \& Scutchfield, 2009; Lehoux, Daudelin, \& Abelson, 2012) and developing standards for emerging technologies (Hamlett, 2003).

The use of public deliberation in higher education requires a shift from a teaching paradigm to a learning paradigm (Barr \& Tagg, 1995). This transition requires teachers to move from simply providing instruction and delivering content to the more complex endeavor of

Journal of the Scholarship of Teaching and Learning, Vol. 14, No. 1, February 2014. 
facilitating learning and empowering students to take charge of their learning (Barr \& Tagg, 1995). Adopting a learning paradigm in the classroom has been shown to increase student engagement and student outcomes (Brank \& Wylie, 2013; Nikitina; 2010). Public deliberation as a teaching andragogy aligns with the learning paradigm as the teacher acts as a guide through the public deliberation process as opposed to delivering content about the process to students. Students undertake a process of discovery and have significant latitude to name and frame options about a public issue in the deliberation process (Melville et al., 2006). In the deliberation process, students work alongside teachers to engage in reflective, often transformational, dialogue in which they gain self-awareness and discover multiple possibilities for collective action (Diaz \& Gilchrist, 2010; Waghid, 2006).

\section{Deliberation on College Campuses}

The use of public deliberation on college campuses is not widespread (Dedrick, Grattan, \& Dienstfrey, 2008), despite its implicit connections to the learning paradigm (Barr \& Tagg, 1995) and demonstrated effectiveness as a tool for making decisions (Walters, 2008). Those institutions utilizing public deliberation tend to concentrate deliberations within campus programs, between the campus and the community, or within administrative and governance structures (Diaz \& Gilchrist, 2010). Diaz and Gilchrist contend that, within these settings, public deliberation addressed timely issues of diversity and social justice, encouraged peer mediation, resulted in more inclusive procedural processes, and promoted active civic engagement. Through this collaborative and inclusive approach, student perspectives are shared and promoted which facilitates conversation toward understanding. By modeling democratic processes, students gain understandings and experience in mutually resolving real world problems, rather than debating them (McMillan \& Harriger, 2007). Diaz and Gilchrist (2010) add that this type of dialogue is the foundation for public deliberation and that such dialogue promotes student participation and empowerment through shared experiences and exposure to a variety of perspectives, not just those of experts. McMillan and Harringer (2007) emphasized that, through deliberative activities, students learn to become active and engaged participants in the democratic processes that occur on campus and nearby communities.

Walters (2008) added that public deliberation can assist institutions of higher learning in transformational change when embedded throughout the college experience. His study revealed a campus-wide shift from teaching to learning following the implementation and expansion of deliberative practices over an eight-year period. Students demonstrated greater flexibility, engagement, and community skills, and were more likely to challenge themselves and others. While not entirely attributable to public deliberation on campus, Walters noted an enhanced learning environment and increased enrollment and public recognition.

Within the classroom, deliberation has been shown to be an effective mechanism to achieve higher-order critical thinking skills (McMillan \& Harriger, 2007; Waghid, 2006). Through deliberation in classroom settings, students are forced to consider conflicting opinions, diverse options for action, and must synthesize multiple voices (Diaz \& Gilchrist, 2010), which have been shown to bolster student learning (Broadbear, 2012). Public deliberation allows students to experience real world situations from within the classroom setting. Through the public deliberation process, students reflect upon educational problems, gain a better understanding of complex problems, and work toward making informed choices about possible lines of action to solve educational problems (Waghid, 2006). 
In a comprehensive study of 30 undergraduate students using public deliberation over four years at Wake Forest University, McMillan and Harriger (2007) offer the most comprehensive data on how deliberation affects college students. Their longitudinal study showed that students were more involved in traditional venues of political action outside of service, attuned to the responsibilities of active citizenship, analytical and critical of political processes and their role in them, efficacious in their political attitudes and language, communal in their political language and outlook, and imaginative in recognizing possibilities for deliberation and applying deliberative knowledge and skills to a broad range of situations. They also note that despite initial hesitation concerning the deliberative process, students experienced a profound change in their attitudes about the process.

Other research on the impact of public deliberation in the classroom has shown that public deliberation led to gains in students' interpersonal awareness and connections with others (Diaz \& Gilchrist, 2010), content knowledge of issues (Daniels \& Walker, 1996), ability to make informed decisions (Blomquist \& Ostrom, 2008; Burgh and Yorshansky, 2008), connections to public issues (Diaz \& Gilchrist, 2010), and group collaboration (Dedrick et al., 2008). An important limitation of these studies is that traditional-aged college students were the primary sample, thus limiting its applicability to non-traditionally-aged populations.

\section{Andragogical Considerations}

The National Center for Educational Statistics (NCES), in their most current completed data, reported the enrollment of adult students over the age of 25 to be nearly nine million of the total 21 million students in higher education, equaling $43 \%$ of all enrolled college students (NCES, n.d.). Since 2000, the number of adults pursuing a postsecondary education has increased by two-and-half-million students after a decade of consistent enrollment, a nearly 30\% increase (NCES). Soares (2013) revealed that only about $15 \%$ of current undergraduates are "traditional" college students; students who are 18-22 years old, attend a four-year college fulltime, and reside on-campus. Soares (2013) adds that adult learners are predominantly part-time students and have significant familial, work, and time commitments outside of taking courses. Consequently, the necessity of catering to adult learners' needs is increasingly important in higher education.

Lindeman (2011) distilled several key assumptions about adult learners from the literature, which constitute the foundation of adult learning theory: Adults are motivated to learn as they experience needs and interests that learning will satisfy, adults' orientation to learning is life-centered, experience is the richest source for adult's learning, adults have a deep need to be self-directed, and individual differences among people increase with age. These key empirical tenets of adult learners, originally conceptualized by Knowles (1984), serve as the foundation for understanding adult learners in the classroom. The use of public deliberation is a useful andragogy because it focuses on what people hold valuable, highlighting everyone's voice, honoring personal experience, and creating opportunities for self-directed learning (Melville et al., 2006).

\section{Methods}

The research question guiding this study was, "What are students' experiences using public deliberation as a teaching andragogy in the classroom?" To better understand students' 
experiences using public deliberation as a teaching andragogy, a qualitative case study was employed (Stake, 1995). Case studies focus on a unit of analysis in a real-life, contemporary setting (Yin, 2008). The purpose of this study was to examine adult learners' experiences using public deliberation as a teaching andragogy in a single course, which suggests the presence of a bounded system (Stake, 1995). Eleven students were part of the course, of which nine elected to participate in the study. Students were part of a doctoral program in higher education administration at a mid-sized, public, four-year university in the Midwest. Students were a mix of full-time and part-time doctoral students. Each student identified as an adult learner. The course was taught by an Assistant Professor of Educational Leadership. Constituting the sole assignment for the course, students were charged with creating a deliberative issue book reflective of the NIF issue books that named and framed a higher education policy issue for public deliberation. Students worked in self-selected small groups, two to four students, designing the issue book on a higher education topic of their choosing. The students addressed timely issues such as college access, internationalization, and undocumented students. Each group produced a 10-17 page issue booklet that presented, in detail, a definition of the problem (naming), possible courses of action, and the potential tradeoffs of each (framing). As doctoral students, connecting to the scholarly literature in the naming and framing was required. Upon completion of the issue booklet, students facilitated a public deliberation forum in class. Steps for the deliberation process were provided by the instructor and based upon National Issues Forums moderator guides (www.nifi.org). These guides outline the role of the moderator, provide steps to moderating a forum, and offer helpful tips on how to moderate a forum to keep the discussion moving and focused on the issue. At the end of the semester, the instructor administered an open-ended, five-question survey (see Appendix) to the students through a survey tool on Blackboard Learn. Surveys were anonymous to encourage honest feedback about students' experiences. The survey asked students to retroactively assess their initial attitudes toward the course and the public deliberation process as the primary teaching andragogy in addition to the project and their final overall experiences using public deliberation in the course.

\section{Data Analysis}

To analyze the survey data, two members of the research team independently coded the transcripts using both open and axial coding (Strauss \& Corbin, 1990), which allowed for an indepth examination of each line of text. Similar concepts and ideas from those initial open codes were then grouped to form themes. To develop analytic triangulation, Patton (2002) argued that when more than one researcher codes data, researchers should first work independently to develop codes and then meet as a group to compare and contrast their interpretations. When independent axial codes were combined into themes, two members of the research team met to build consensus on themes and findings. Additionally, participants also served as authors in this manuscript, which provided a source of member checking (Patton, 2002). Students were encouraged to correct misinterpretations of data in the manuscript. Inductive analysis (Patton, 2002) was used to forefront students' experiences using public deliberation. Letting the patterns, themes, and categories emerge from the data allowed for a more robust understanding of students' experiences. 


\section{Results}

Results of this study yielded five important themes regarding adult students' experiences using public deliberation in the classroom: students experienced initial nervousness, hesitancy with group projects, an understanding of multiple perspectives, an ability to weigh tradeoffs, and an increase in student agency. Each theme is discussed individually, followed by implications for practice and research.

\section{Initial Nervousness}

When students learned about deliberation on the first night of class, each expressed a cautious excitement that contained some elements of nervousness. Since deliberation was unfamiliar to them, their nervousness was palpable. One student remarked, "I was nervous, and what was going through my mind all through the class period was "how different this assignment would be." Another student admitted a strong feeling of being "overwhelmed." Since the class used a public deliberation andragogy throughout the semester, students were concerned with an unfamiliar andragogy as the basis for the entire course. More than simply the foundation of the course, public deliberation would also constitute the primary source of students' grades. Many students remarked that because this process was so unfamiliar to them, and that it would determine their entire grade, they were uneasy. "To be completely honest, there were some mixed emotions about having this project be the foundation for my entire grade," one student admitted. Unfamiliarity with the andragogy coupled with the group nature of the public deliberation project caused trepidation and nervousness for each student. These feelings may be interpreted in the light of Knowles' (1984) principle that adult learners must see the utility in their learning to be motivated to learn. An unfamiliar andragogy, such as public deliberation, initially challenged students' ability to see its utility.

While all of the students indicated some level of anxiousness, some students welcomed the innovative andragogy. "I think what excited me most was hearing that using public deliberation as a learning tool had not been attempted before in the program. I love taking part in new learning methodologies and this sounded exciting," one student expressed. Another student expressed being "up for the challenge," which indicated that, for at least some students, a level of excitement lurked below the surface of their anxiousness.

\section{Hesitancy with Group Projects}

Perhaps not surprisingly, students were concerned about public deliberation because of the immense amount of group work involved. Naming and framing an issue for public deliberation and creating an issue book so others can deliberate the issue requires sustained interaction with a group. Many students confessed to having relied on the "divide and conquer" method of tackling group projects, in which students divide the workload into smaller pieces, work individually, and then bring their pieces back to the collective to be integrated into the larger project. This tried and true method did not work well for public deliberation and presented

a challenge for the students due to the extensive commitments outside of the class typical of adult learners (Soares, 2013). As one student plainly stated,

With every group member having other obligations outside of the classroom, it was sometimes difficult to properly collaborate on ideas. For example, if one member set 
aside four hours on a Saturday evening to work only on the project but needed input from the other members before he/she could proceed, but the other members were taking care of other obligations and couldn't respond, it could be very frustrating for the member trying to utilize what little free time that was available.

This student's remarks illustrate how challenging public deliberation can be with adult learners. Another student reflected, "I always find group work the most challenging. It is difficult to get so many people together, function as a machine and produce a quality product in such a short time." These two comments show that as adult learners worked to balance multiple commitments, spending prolonged time with group members to work through the intricacies of naming and framing an issue for public deliberation became challenging.

\section{An Understanding of Multiple Perspectives}

The public deliberation process allowed students to see multiple perspectives and to discern the grey areas in policy matters more clearly. Public deliberation issue books usually have three or four possible approaches to address a particular problem, which inherently presents multiple perspectives and avoids the illusion of "one right answer." As one student summarized, "By using public deliberation, people can meet in the middle on issues rather than feeling obligated to choose sides." Students were able to see multiple points of view, what values were associated with those views, and what courses of action were associated with those views. Hearing multiple perspectives made for an enjoyable experience, as students were excited to be part of an inclusive, thoughtful process. One student commented, "I always find it intriguing to hear others' points of view and question why they feel that way especially when I don't see things from that point of view. It helps broaden my perspective."

Additionally, students remarked on how deliberation provided a "civil" way to discuss issues - likely contrasting dominant models of discussing policy, which can be uncivil. As one student noted,

[Public deliberation] can really allow people to understand the importance of the policy issues, and allows for civilized discussion of the possible actions that could be taken, as well as any trade-offs of those actions. It provides a way for communities to realize the values that people hold surrounding higher education and do so in a way that makes people want to continue to talk about them.

Another student commented, "Public deliberation is very different from group work or large group discussions where the loudest, most persuasive voice usually dominates the group, or a paper that furthers the writer's perspective." Public deliberation fosters civil discussion about issues, which helped promote students' learning.

As students deliberated civilly about higher education policy, they were more apt to hear multiple voices. Hearing multiple perspectives pushed students' thinking about higher education policy issues out of dichotomous thinking to more nuanced understandings. As students heard others' views, and had the opportunity to carefully weigh others' thoughts alongside their own, students could arrive at a more sophisticated understanding of higher education policy issues. Students attributed public deliberation andragogy to their increased understanding of higher education policy. "It allowed me to internally absorb information that I had researched and then apply the knowledge through my writing. I felt like this allowed me to master the material in a way I otherwise would not have been able to." Because students had to present "all sides" of an issue for the issue book, they had to actively take on those perspectives and seek 
understanding. This resulted in an increased consideration of the content material, which all of the students in the study noted.

Although the research design did not allow for longitudinal outcomes, two students alluded to the enduring impact of deliberation. "Once a student has participated in conducting their own deliberation, it is difficult to see issues from only one perspective with little regard for the consequences of those decisions." Another student remarked, "This process has me thinking about how I can use public deliberation in other areas of my work." These comments suggest that the impact of students' participating in public deliberation may be long-term.

\section{An Ability to Weigh Tradeoffs}

In addition to presenting multiple perspectives, public deliberation forces participants to consider tradeoffs associated with various courses of action - a part of deliberation that every student in the study found valuable. For instance, for students who might be in favor of increasing the amount of student aid for college students, they are forced to think through the likely tradeoff of paying more taxes, which may or may not be a tradeoff they are willing to accept. Considering likely tradeoffs made students think more deeply about the material and who might be affected by various decisions. This gave students a broader perspective from which to operate and understand higher education policy.

Each of the nine students in the study mentioned the value of weighing tradeoffs associated with action steps. One student reflected, "Spending the time to really think through both the positive and negative consequences of each potential action, through many different lenses, helped reinforce the gravity of the issue." Another opined, "Public deliberation can really allow people to understand the importance of the policy issues, and allows for civilized discussion of the possible actions that could be taken, as well as any trade-offs of those actions." This student continued, "Weighing tradeoffs makes the issue real because it requires a sacrifice of some sort." These students' comments highlight the importance of weighing the costs when considering proposed courses of action. Doing so helped students' see the issue(s) in a more nuanced way and provided them with a clearer understanding of proposed action steps or solutions.

\section{Increased Student Agency}

As students became more involved in the public deliberation project, they developed a sense of ownership and agency. Students reported feeling a sense of ownership over the process and content of the project. They felt as though what they were doing was building their selfefficacy and confidence to engage in higher education policy. One student stated, "Public deliberation as a teaching method encourages participation as opposed to traditional teaching methods such as lecture, group work, or an academic paper." Another remarked, "Having simply discussed this in class, or written a paper on the process wouldn't have given me confidence I now have to go through the process in a real-life situation." Another student remarked, "While there is a place for lecture within the classroom, it never encourages the development of the student's perspective, a valuable piece obtained through deliberation." Developing students' selfefficacy in understanding and acting upon higher education policy issues is a difficult feat, but public deliberation offers an andragogy to build these capacities. One student even remarked, "It 
felt like students were turned into teachers," which provides even greater evidence of how public deliberation creates a sense of ownership and fosters student agency.

The nature of the course is particularly important to consider. Students commented that higher education policy can seem distant and unapproachable. Federal and state policies on student loans, immigration, financial aid, or affirmative action can feel unapproachable unless one works in policy making. Deliberation helped students identify ways they could affect these issues by focusing the onus of action on them and other stakeholders. One student simply stated, "I had the agency to engage what concerned me most." Since public deliberation engages what people hold valuable about higher education (e.g., keeping college affordable, equality in education), students felt more connected to the issue and were better able to identify action steps they could take to affect policy. One student found value in this aspect of public deliberation:

I appreciated the opportunity to focus on topics of direct interest to me and others in my group. This allowed [us] to master the material and decide what we could do. We could establish common ground and ways we could proceed.

Finding one's place and identifying steps for action are important aspects of public deliberation and students echoed their importance.

\section{Discussion and Implications}

The results of this case study hold several implications for practice. First, public deliberation carries considerable promise for fostering the learning of adult students. Instructors would likely agree that three of the five themes from this study constitute vaunted learning outcomes (i.e., understanding multiple perspectives, increasing student agency, evaluating tradeoffs associated with action). Public deliberation was shown to help achieve these learning outcomes, which is corroborated by other studies (Dedrick et al., 2006; McMillan \& Harriger, 2007).

In particular, public deliberation was shown to increase student agency - an important aspect of adult learning theory (Knowles, 1984; Lindeman, 2011). As Knowles (1984) argued, adults have a deep psychological need to be self-directed learners. Public deliberation inherently requires self-directed learning, as students are responsible for naming and framing an issue for public deliberation. Doing so requires students to take charge of their own learning and mutually construct an issue book based on their groups' understanding of the issue. Public deliberation as an andragogy is therefore an appropriate fit for adult learners based on Knowles' characteristic of self-direction in adult learners.

Another implication for practice is that public deliberation may be an important vehicle for making complex content more accessible and practical for students. Higher education policy can feel inaccessible to students because policy is often viewed as something elected officials or prominent college administrators do. A new professional or graduate student in higher education may feel as though they do not have a role in policy matters. As one student remarked, "Policy is something that happens at 30,000 feet." Public deliberation can help students conceptualize an issue and determine their roles in taking action. In essence, public deliberation can be an effective tool for affecting change and taking collective action because it helps students better understand the issues and places them within the issues, therefore making action more likely. This finding relates to Knowles' (1984) characteristic of adult learners possessing vast life experiences that serve as the richest source for their learning. Public deliberation invites students to bring in personal experience (Melville et al., 2006), which may help students feel more 
connected to the issue. By leveraging adult learners' significant life experiences, public deliberation provides a rich opportunity to foster student learning.

Educators may find that public deliberation provides a framework for meaningful and engaging group projects. As students indicated, public deliberation requires an immense amount of group coordination and dialogue, which fostered some initial resistance. How does one counter students' apprehension of a group project, which several adult learning theorists, such as Brookfield (1991) and Cranton (2006), have identified as an important pedagogical component? These theorists suggest considering asynchronous group projects, where students do not have to work on a group project at the same time. Public deliberation presents a challenge to this suggestion because public deliberation andragogy usually requires people synchronously working together. Since adult learners tend to have significant familial and career obligations outside of school (Soares, 2013), exploring ways to facilitate synchronous group work in public deliberation would enhance its utility and application for adult learners. In this study, the instructor set aside time for students to plan, discuss, and work together on their project. The instructor was available to answer questions, provide direction, and assess group dynamics during this time.

Educators should also consider how to evaluate students' work on a public deliberation project. Students in this study described considerable apprehension about an unfamiliar andragogy and project as the sole basis of their grade. Further, the instructor made the determination that students would not receive individual grades for their work; rather, students would receive a group grade. Public deliberation requires group work at all levels-naming, framing, deliberating, deciding what to do next - which begs the question of how to separate grading considerations. Unless there is a problematic group member, how does one assign different grades to students when the finished product (i.e., the issue book) is a reflection of hours of intense discussion and reworking of the naming and framing? Educators could seek to add individual reflection components or action plans to help offset the issues that often accompany a group grade.

Related to the prior implication of considering public deliberation as an andragogy, a few cautions should be heeded. First, understanding public deliberation requires a thorough research and reflection of the intent, process, and design. Those interested in adopting public deliberation in their classrooms should familiarize themselves with the theory and process. While the process of public deliberation helps participant's finds common ground for action when working with complicated societal topics, this process may not be useful in all classroom situations. Second, according to a Kettering Foundation report (2011), the deliberative process is only appropriate when participants are aware of a problem but are unsure or unable to identify exactly what is at stake. Issues that are too broad, or decisions have already been made, or the issue requires technical or managerial solutions are also not a good fit for the deliberative process. A sound issue for deliberation typically centers around perspectives with a moral or value based foundation; such issues cannot simply be solved through traditional classroom or community discussion or debate. In this manner, public deliberation is distinct from dialogue, debate, and other forms of discussion typically used in educational settings. The National Issues Forum (www.nifi.org) provides a host of resources for educators interested in public deliberation. After gaining a more nuanced understanding of public deliberation, educators should then determine if public deliberation is an appropriate fit for their intended learning outcomes. 


\section{Limitations}

Readers should consider several limitations when reflecting on the results and implications of this study. First, data about students' experiences in the course were gathered at the end of the course. Students were asked to retrospectively assess their initial reactions to the instructor's use of a public deliberation andragogy and their subsequent learning. This practice is common in research (Creswell, 2007), but detailed reflections throughout the course would likely have produced more robust data. Second, two of the eleven students in the course declined to participate for undisclosed reasons in the research study. Having their voices reflected in this research would have provided a more complete picture of our collective experiences, and perhaps even provided a negative case (Stake, 1995). Finally, the fact that time constraints did not permit students to deliberate with members of the larger campus or regional community limited the impact of our collective work. Doing so would have broadened the impact of our work and more accurately reflected the true nature of public deliberation (McMillan \& Harriger, 2007).

\section{Conclusion}

This study explored the use of public deliberation as a teaching andragogy. The instructor used public deliberation as a teaching andragogy in a doctoral higher education policy class and this model gave students voice, agency, ability to weigh tradeoffs, and the opportunity to make informed contributions to important higher education issues. This andragogy helped students to see themselves not just as passive students, but as stakeholders, actors, and participants whose views and contributions were central in the educational decision-making process. When students are given agency to explore their own academic inquiries, they tend to produce more quality outcomes and report greater learning than being passive recipients of knowledge (Knowles, 1984). Public deliberation provides an environment to build student agency and foster student learning. Although the participants of this study expressed initial nervousness because public deliberation was unfamiliar to them as a teaching andragogy, the overall results indicated that students were able to see multiple perspectives, weigh tradeoffs, and experienced increased student agency in the process. Public deliberation is thereafter a promising andragogy that enhances student learning.

Furthermore, the importance of public deliberation in the twenty-first century classroom is crucial given the multi-faceted nature of knowledge in the present digital age and the increasing number of adult learners (Soares, 2013). Technologically and demographically, students are more aligned to instructional contents that allow them play active roles in the formation of knowledge. Hence, there is a paradigm shift in how knowledge is constructed (Barr \& Tagg, 1995) as adult learners are more interested in an education that allows them have autonomy and freedom to pursue their inquiries in areas that interest them most (Lindeman, 2011). Our experience with public deliberation showed that public deliberation creates greater ownership of the course, fosters critical thinking and student agency, and implicates taking action. Public deliberation may hold the key to creating an adult learning environment rich with these attributes. 


\section{Appendix}

Appendix 1. End of Semester Student Survey

1. What were your initial reactions when you learned that the main assignment for this course would be on naming and framing a higher education policy issue for public deliberation?

2. What did you find to be most rewarding about the public deliberation project?

3. What did you find most challenging about the public deliberation project?

4. What benefit does public deliberation have for addressing higher education policy issues?

5. What did public deliberation as a teaching method do to benefit your learning as opposed to other teaching methods (e.g., lecture, traditional academic paper)?

\section{References}

Barr, R. B., \& Tagg, J. (1995, November/December). From teaching to learning: A new paradigm for undergraduate education. Change, 27(6), 12-25. doi:

10.1080/00091383.1995.10544672

Blomquist, W., \& Ostrom, E. (2008). Deliberation, learning, and institutional change: The evolution of institutions in judicial settings. Constitutional Political Economy, 19(3), 180-202. doi: $10.1007 / \mathrm{s} 10602-008-9045-5$

Brank, E., \& Wylie, L. (2013). Let's discuss: Teaching students about discussions. Journal of the Scholarship of Teaching and Learning, 13(3), 23-32.

Broadbear, J. (2012). Essential elements of lessons designed to promote critical thinking. Journal of the Scholarship of Teaching and Learning, 3(3), 1-8.

Brookfield, S. D. (1991). Understanding and facilitating adult learning: A comprehensive analysis of principles and effective practices. San Francisco, CA: Jossey-Bass.

Burgh, G., \& Yorshansky, M. (2008). Communities of inquiry: Politics, power and group dynamics. Educational Philosophy and Theory, 43(5), 436-452. doi: 10.1111/j.14695812.2007.00389.x

Cranton, P. (2006). Understanding and promoting transformative learning: A guide for educators of adults ( $2^{\text {nd }}$ ed.). San Francisco, CA: Jossey-Bass.

Creswell, J. W. (2007). Qualitative inquiry \& research design $\left(2^{\text {nd }}\right.$ ed.). Thousand Oaks, CA: SAGE.

Daniels, S. E., \& Walker, G. B. (1996). Collaborative learning: Improving public deliberation in ecosystem-based management. Environmental impact assessment review, 16(2), 71-102. doi: 10.1016/0195-9255(96)00003-0 
Johnson, M., Partlo, M., Hullender, T., Akanwa, E., Burke, H., Todd, J., \& Alwood, C.

Dedrick, J. R., Grattan, L., \& Dienstfrey, H. (Eds.). (2008). Deliberation and the work of higher education: Innovations for the classroom, the campus, and the community. Dayton, $\mathrm{OH}$ : Kettering Foundation.

Diaz, A., \& Gilchrist, S. H. (2010). Dialogue on campus: An overview of promising practices. Journal of Public Deliberation, 6(1), 9.

Downey, L. H., Anyaegbunam, C., \& Scutchfield, F. D. (2009). Dialogue to deliberation: Expanding the empowerment education model. American Journal of Health Behavior, 33(1), 2636. doi: 10.5993/AJHB.33.1.3

Hamlett, P. W. (2003). Universities and public deliberation: Bringing expertise to the people. $O n$ the Horizon, 11(4), 15-24. doi: 10.1108/10748120310508046

Harris, C. C., Nielsen, E. A., Becker, D. R., Blahna, D. J., \& McLaughlin, W. J. (2012). Results of community deliberation about social impacts of ecological restoration: Comparing public input of self-selected versus actively engaged community members. Environmental Management, 50(2), 191-203. doi: 10.1007/s00267-012-9871-0

Kettering Foundation (2011). Naming and framing difficult issues to make sound decisions. Retrieved from: http://ncdd.org/rc/wp-content/uploads/2010/08/NamingAndFraming.pdf

Knowles, M. S. (1984). The adult learner: A neglected species ( ${ }^{\text {rd }}$ ed.). Houston, TX: Gulf.

Lehoux, P., Daudelin, G., \& Abelson, J. (2012). The unbearable lightness of citizens within public deliberation processes in healthcare. Social Science \& Medicine, 74, 1843-1850. doi: 10.1016/j.socscimed.2012.02.023

Lindeman, E. (2011). The meaning of adult education. Charleston, SC: Nabu.

McMillan, J. J., \& Harriger, K. J. (2007). Speaking of politics: Preparing college students for democratic citizenship through deliberative dialogue. Dayton, $\mathrm{OH}$ : Kettering Foundation Press.

Melville, K., Willingham, T. L., \& Dedrick, J. R. (2006). National Issues Forum: A network of communities promoting public deliberation. In J. Gastil \& P. Levine (Eds.), The deliberative democracy handbook: Strategies for effective civic engagement in the twenty-first century (pp. 37-58). San Francisco, CA: Jossey-Bass.

Muse, W. V. (2009). Public Deliberation: The Kettering Foundation's Experience and Opportunities for the Engaged University. Journal of Higher Education Outreach and Engagement, 13(3), 61-63.

National Center for Educational Statistics (n.d). Total fall enrollment in degree-granting institutions, by attendance status, sex, and age: Selected years, 1970 through 2020. Retrieved from: http://nces.ed.gov/programs/digest/d11/tables/dt11_200.asp

Journal of the Scholarship of Teaching and Learning, Vol. 14, No. 1, February 2014. 
Johnson, M., Partlo, M., Hullender, T., Akanwa, E., Burke, H., Todd, J., \& Alwood, C.

Nikitina, L. (2010). Addressing pedagogical dilemmas in a constructive language learning experience. Journal of the Scholarship of Teaching and Learning, 10(2), 90-106.

Patton, M. Q. (2002). Qualitative research and evaluation methods (3rd ed.). Thousand Oaks, CA: SAGE.

Soares, L. (2013). Post-traditional learners and the transformation of postsecondary education: A manifesto for college leaders. Retrieved from http://www.acenet.edu/news room/Documents/Soares-Post-Traditional-v5-011813.pdf.

Stake, R. (1995). The art of case study research. Thousand Oaks, CA: SAGE.

Strauss, A., \& Corbin, J. (1990). Basics of qualitative research: Grounded theory procedures and techniques. Newbury Park, CA: SAGE.

Waghid, Y. (2006). University education and deliberation: In defense of practical reasoning. Higher Education, 51(3), 315-328. doi: 10.1007/s10734-004-6388-3

Walters, D. J. (2008). Deliberation, civic discourse, and democratic dialogue in the context of academic change (pp. 198-223). In Deliberation and the work of higher education: Innovations for the classroom, campus, and community. Dayton, $\mathrm{OH}$ : Kettering Foundation.

Yin, R. K. (2008). Case study research: Design and methods $\left(4^{\text {th }}\right.$ ed.). Thousand Oaks, CA: SAGE. 